\title{
Peter HÄBerle EN EL Siglo XXI
}

\author{
Miguel AZPITARTE-SÁNCHEZ ${ }^{\dagger}$
}

\section{Un Homenaje A Peter HÄBERLE}

Paraules Clau: Peter Häberle; Crisis Europeas; Pluralismo;

Constitución; Unión Europea.

PAlaVRAS-Chave: Peter Häberle; Crises Europeias; Pluralismo;

Constituição Estatal; União Europeia.

KEYWORDS: Peter Häberle; European Crisis; Pluralism; Constitution; European Union.

\footnotetext{
† Profesor Titular de Derecho Constitucional em la Universidad de Granada, España.
} 


\section{Mesa de Contenido:}

I. INTRODUCCIÓN ………...........................................................................61

II. TRES CRISIS EUROPEAS:

un CONTEXTo PARa El TEXTO DEL Profesor HäBerLe................62

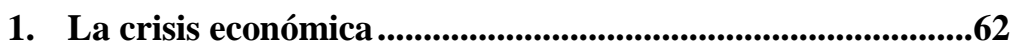

1.1. El Estado competitivo ..................................................63

1.2. La deconstrucción del elemento trabajo.........................65

1.3. La politización de la Unión Europea..............................66

1.4. La (parcial) despolitización del Estado...........................67

2. La crisis de seguridad ...................................................................68

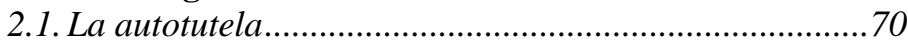

2.2. La acción estatal preventiva ...........................................71

2.3. La excepción normalizada y la militarización del discurso político .............................................................72

3. La crisis política .................................................................................73

3.1. Nuevos conflictos, viejos instrumentos ............................73

3.2. En busca del conflicto contemporáneo ........................... 75

III. La Utilidad del Pensamiento de Peter Häberle ANTE EL ESCENARIO CONTEMPORÁNEO: UNA GUÍA DE TRABAJO.....................81

1. El pluralismo como premisa ....................................................81

2. Sobre la función de la Constitución estatal...............................82

3. Sobre la función constitucional del derecho de la Unión.....83

4. Los fines del Estado ...................................................................85

IV. REFERENCIAS............................................................................................86 


\section{SUMÁRIO:}

I. INTRODUÇÃO ..................................................................................................61

II. TRÊS CRISES EUROPEAS: UMA CONTEXTUALIZAÇÃO PARA O

TEXTO DO PROFESSOR HÄBERLE........................................................62

1. A crise econômica............................................................................62

1.1. O Estado competitivo...................................................63

1.2. A desconstrução do elemento trabalho............................65

1.3. A politização da União Europeia ....................................66

1.4. A (parcial) despolitização do Estado..............................67

2. A crise de segurança .................................................................68

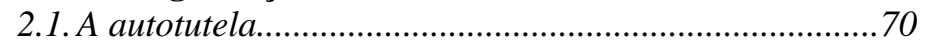

2.2. A ação estatal preventiva...............................................71

2.3. A exceção normalizada e a militarização do discurso político ................................................................72

3. A crise política.....................................................................................73

3.1. Novos conflitos, velhos instrumentos.............................73

3.2. Em busca do conflito contemporâneo.............................75

III. A Utilidade do Pensamento de Peter Häberle diante do

CENÁRIO CONTEMPORÂNEO: UM GUIA DE TRABALHO.......................81

1. O pluralismo como premissa.........................................................81

2. Sobre a função da Constituição estatal .....................................82

3. Sobre a função constitucional do direito da União ................83

4. Os fins do Estado..................................................................85

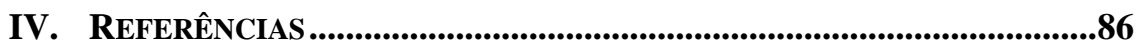




\section{TABLE OF CONTENTS:}

I. INTRODUCTION ...................................................................................61

II. Three European Crisis: a ConteXtualization to Professor

HÄBERLE'S ESSAY …………………………..............................................62

1. The economic crises .....................................................62

1.1. The competitive State .................................................63

1.2.The deconstruction of the element labor .......................65

1.3.The politization of European Union..............................66

1.4. The (incomplete) State depolitization ..........................67

2. The security crises..................................................................68

2.1. The self-protection .................................................70

2.2. The preventive State action........................................71

2.3. The ordinaryness of exception and the militarization of political discourse................................................ 72

3. The political crises ..........................................................73

3.1. New conflicts, old tools..........................................73

3.2. In search of the contemporary conflict ......................75

III. The UTILITY OF PETER HÄBERLE'S THOUght BEFORE THE CONTEMPORARY SCENARIO: A WORKING GUIDE............................81

1. The pluralism as a premise .....................................................881

2. About the role of the Constitution ...........................................882

3. About the constitutional role of the Union Law ....................83

4. The State ends ....................................................................85

IV. REFERENCES ........................................................................86 


\section{INTRODUCCIÓN}

Los editores de la Revista me proponen dialogar con el profesor Peter Häberle a partir de su texto, que ofrece una mirada sintética sobre los conceptos elaborados en su fructífera carrera. La labor es un reto, porque quien escribe estas líneas sabe de sobra que la conversación se entabla con un gigante. No obstante, el desafío merece la pena, siquiera por razones personales, dado que me siento con fuerzas para reivindicar al profesor Häberle como mi maestro alemán; durante el curso 1999/2000 pasé un año académico en la Universidad de Bayreuth, periodo después del cual siempre me ha regalado su afecto y su guía. Además, la posibilidad de escribir sobre el pensamiento de Peter Häberle en una revista brasileña me es de especial alegría, ya que dos fueron las veces en que conjuntamente recorrimos de norte a sur el país, disfrutando de la hospitalidad y del alto nivel académico de los colegas brasileños. De aquellos tiempos, seguro, nace esta invitación.

En las páginas que siguen no voy a analizar el pensamiento de Peter Häberle. Esa tarea ya la intenté en mi ensayo "Apuntes del pensamiento de Peter Häberle en el contexto de la dogmática alemana", publicado en el año 2003 por la Revista de la Facultad de Derecho de Granada ${ }^{1}$. Lo que pretendo ahora es retomar un hilo con el que cerré aquel trabajo, en el que afirmaba:

Esta actualización constante de la tradición, señalándole nuevos derroteros, es el elemento propio de toda obra clásica. Sin embargo, calificar al profesor Häberle como un "clásico en vida" es todavía un defecto por exceso que seguramente él no aceptaría. Si la obra clásica es aquella que goza de permanente elocuencia más allá del momento de su elaboración, resulta evidente que aún carecemos de la conciencia histórica suficiente para

\footnotetext{
${ }^{1}$ Por lo demás, una visión general de la obra de Peter Häberle podemos adquirirla en el excelente libro de entrevistas DIEGO VALADÉS, CONVERSACIONES ACADÉMICAS CON PETER HÄBERLE (2006), disponible en $<$ http://biblio.juridicas.unam.mx/libros/libro.htm?l=1854>, visitada el 22 de mayo de 2016. Asimismo, me remito a mi traducción de aparición en el núm. 25 de la Revista de Derecho Constitucional Europeo y que lleva por título provisional, Andreas Voßkuhle y Thomas Wischmeyer, El jurista en su contexto. Peter Häberle en su ochenta cumpleaños (publicado en alemán: Andreas Voßkuhle y Thomas Wischmeyer, Der Jurist im Kontext: Peter Häberle zum 80. Geburtstag, JAHRBUCH DES ÖFFENTLICHEN RECHTS DER GEGENWART, No. 63, 2015).
} 
imputar al pensamiento de Häberle tales atributos. Es más, sumidos en el escepticismo sobre el progreso lineal de la historia política occidental, un pensamiento radicalmente democrático como el de Häberle corre el riesgo de ser olvidado en los años venideros.

¿Dónde estamos trece años después? Mi referencia al "escepticismo sobre el progreso lineal de la historia política occidental" parece haberse cumplido, puesto que el horizonte europeo está cubierto de sombras (mi aportación, ha de ser eurocéntrica, porque mi conocimiento de otras realidades es nulo; espero, sin embargo, que de algún modo estas reflexiones puedan extenderse a Latinoamérica). En el primer epígrafe intentaré definir las tres crisis que aquejan al viejo continente y en qué medida ponen en cuestión la funcionalidad del derecho constitucional. En el segundo epígrafe reflexionaré sobre la utilidad de los conceptos häberlianos para comprender y dirigir la nueva realidad.

\section{TRES CRISIS EUROPEAS: UN CONTEXTO PARA EL TEXTO DEL} PROFESOR HÄBERLE

\section{La crisis económica}

La bibliografía sobre la crisis económica es ingente, por ello siempre será discutible el intento que pretenda aprehender sus elementos básicos ${ }^{2}$. No obstante, en estas páginas el esfuerzo es necesario para trazar el terreno común de las circunstancias que han condicionado el devenir de nuestra realidad constitucional en la última década. En este sentido, se ha de comenzar reseñando que la crisis económica se manifiesta a partir de 2008, poniendo fin a un largo periodo de casi otros diez años, la llamada "great moderation", distinguida por un periodo de crecimiento económico constante, con leve inflación y bajo desempleo. En aquel entonces se incentivó la liquidez crediticia, que acabaría perturbando el funcionamiento de los sistemas bancarios, básicamente su capacidad para estimar correctamente el valor de los activos que financiaban, en

2 Por ejemplo, desde un punto de vista puramente económico, William van Lear, Portfolio Shifts, Asset Price Declines, and Liquidity Lock Understanding the 2007-2009 Financial Crisis, 39 INTERNATIONAL JOURNAL OF POLITICAL ECONOMY 3, 2010. Una perspectiva atenta a la peculiaridad jurídica de la Unión Europea, Armin Curveys, The Sovereign Debt and EMU crises: A perfect confederal storm?, LEIDEN UNIVERSITY REPOSITORY, 2013. 
especial los inmobiliarios. La espiral de las hipotecas subprime en Estados Unidos terminaría por provocar un efecto dominó sobre el sistema financiero internacional, llevando a muchos de los bancos europeos a una situación límite, que exigió la intervención supletoria del dinero público para sostener la operatividad de la función bancaria. Finalmente, la crisis de deuda privada devino en crisis de deuda pública, provocando un recorte masivo del gasto público y una reducción del salario con el fin de disminuir los costes de producción. En conclusión, la Europa del bienestar se ha empobrecido y ofrece a sus nuevas generaciones un horizonte tenebroso.

\subsection{El Estado competitivo}

Del contexto brevemente descrito me interesan los rasgos que apuntan a un nuevo escenario constitucional. El primero, en mi opinión, tiene que ver con el dato, evidente ahora en toda su crudeza, de que el Estado depende para su propia existencia de la financiación cotidiana en los mercados de crédito. Desde la ciencia política, para conceptualizar esta realidad, se ha escogido la categoría de "Estado competitivo", sustituyendo otras hasta ahora dominantes, como la de Estado social o Estado regulador, que se utilizaban para definir la relación del poder público con el mercado ${ }^{3}$.

El Estado social, llevado a su última esencia, se legitima por su capacidad para prestar servicios públicos. ${ }^{4}$. Desde esta premisa, su relación con el mercado es de superioridad, puesto que delimita el terreno en el que opera la iniciativa privada (recordemos la técnica excluyente del

${ }^{3}$ Philip G. Cerny, Paradoxes of the Competition State: the Dynamics of Political Globalization, 32 GOVERNMENT AND OPPOSITION 2, 1997; T. Fougner, The State, international competitiveness and neoliberal globalization: is there a future the competition State?, 32 REVIEW OF INTERNATIONAL STUDIES 1, 2006.

${ }^{4}$ En general, sin ánimo exhaustivo pero reflejando los elementos esenciales del debate véase Konrad Hesse, Observaciones sobre la actualidad y el alcance de la distinción entre Estado y Sociedad, in KONRAD HESSE, ESCRITOS DE DERECHO CONSTITUCIONAL (eds. Miguel Azpitarte-Sánchez y Pedro Cruz Villalón, 2011); Ernst Wolfgang Böckenförde, Die Bedeutung der Unterscheidung von Staat und Gesellschaft im demokratischen Sozialstaat der Gegenwart, in ERNST WOLFGANG BÖCKENFÖRDE, RECHT, STAAT, FREIHEIT: STUDIEN ZUR RECHTSPHILOSOPHIE, STAATSTHEORIE UND VERFASSUNGSGESCHICHTE (1991); Manuel García-Pelayo, El Estado Social y sus implicaciones, in MANUEL GARCÍA-PELAYO, LAS TRANSFORMACIONES DEL ESTADO CONTEMPORÁNEO (1996); y CARLOS DE CABO MARTÍN, LA CRISIS DEL ESTADO SOCIAL (1986).

2 JOURNAL OF INSTITUTIONAL STUDIES 1 (2016) 
monopolio), cuándo puede concurrir con ella (su iniciativa económica es potencialmente ilimitada) y en qué ocasiones prefiere valerse de ella (los contratos públicos). Hoy, el Estado continúa prestando servicios, pero se discute que ahí radique la base de su legitimidad; no en vano, la reducción del Estado es una proclama común desde hace décadas.

En consonancia con tal reivindicación, fue emergiendo en la teoría y en la práctica la idea del Estado regulador, que sin perder de vista la necesidad de asegurar determinadas prestaciones, basaba su legitimidad en la capacidad para generar un contexto normativo en el que el juego transparente y libre de las fuerzas del mercado lograría que esos servicios se dieran de forma más barata y de mayor calidad ${ }^{5}$. De forma paralela, el ciudadano, en su vertiente de consumidor, utilizaba el crédito para acceder a servicios: vivienda, educación, sanidad, etc.; el crédito le permitía organizar su vida de acuerdo con unas ganancias futuras. Las potestades preeminentes del Estado se transformaron y de la gestión directa o indirecta de servicios públicos se pasó a una intervención regulatoria para lograr su efectiva competencia; la administración ordinaria de acción cedió protagonismo a las agencias independientes centradas en inspeccionar y reprimir las prácticas colusorias. Incluso se dio pie a la autorregulación de los actores del mercado, en la confianza de que ellos, antes que el Parlamento o el Gobierno, serían capaces de encontrar la justa medida a las necesidades, generando los servicios básicos con mayor eficiencia.

En el Estado competitivo la superioridad del poder público sobre el mercado se rompe. La prestación de servicios básicos sigue siendo el dato distintivo del Estado; sin ellos simplemente no existe. Pero ahora, no es este quien decide el espacio de la iniciativa privada. El mercado, concretamente el financiero, que nutre la deuda pública del Estado, es quien fija la disponibilidad de liquidez (iy de solvencia!) de los presupuestos públicos, o lo que es igual, delimita de facto la cantidad y calidad de los servicios públicos. La acción estatal, en concurrencia con otros, debe estimular la confianza de los prestatarios, de ahí que un núcleo esencial de su actividad esté orientado a demostrar su capacidad de cumplimiento, aunque deba exigir "sacrificios" a sus ciudadanos.

A nadie se le escapa que esta necesidad de crear confianza cierra otras opciones a los Estados que comparten el euro, como podría ser la

${ }^{5}$ Valga como ejemplo, Giandomenico Majone, The regulatory state and its legitimacy problems, 22 WEST EUROPEAN POLITICs 1, 1999; Martin Lodge, Regulation, the Regulatory State and European Politics, 31 West EuROPEAN POLITICS 1-2, 2008; David Levi-Faur, Regulation \& Regulatory Governance, JERUSALEM PAPERS IN REGULATION \& GOVERNANCE, No. 1, 2010. 
devaluación o la política monetaria expansiva, incluyendo la compra de deuda pública por el Banco Central, que operaría como último pagador (véase en este sentido la respuesta de los Estados Unidos a la crisis'). Así, desde el momento que estas acciones, antaño típicas del Estado, han desaparecido al estar prohibidas por la Unión, la capacidad de competir por obtener la mejor financiación se ha convertido en un fin estatal elemental.

\subsection{La deconstrucción del elemento trabajo}

Siguiendo el hilo del punto anterior, se ha de recordar que el Estado social, en su imagen maestra no se agota con la prestación de servicios. Uno de sus elementos esenciales es, también, la articulación de la dialéctica entre el capital y el trabajo, cuyo conflicto dominó entreguerras y su neutralización ocupó al constitucionalismo de postguerra. La solución que entonces se alcanzó es de sobra conocida: las Constituciones contemporáneas recondujeron el choque capital-trabajo fuera de la dinámica política ordinaria de corte legislativo, y lo encapsularon en un proceso de negociación entre las partes interesadas, que resultaría en un acuerdo con fuerza vinculante. De este modo, las condiciones de trabajo $\mathrm{y}$ en especial el salario encontraron su soporte jurídico en las Constituciones, puesto que la negociación colectiva, la sindicación y los instrumentos de conflicto colectivo, en especial, la huelga, fueron reconocidos como derechos fundamentales en muchos textos constitucionales.

Cualquier observador se habrá percatado de que el intento de solucionar la crisis, más allá de las medidas de contención de gasto, ha pasado por la reducción salarial, que, obviamente, ha tenido como consecuencia palmaria un evidente empobrecimiento de las sociedades europeas, en especial allí donde la situación ha sido más gravosa. En mi opinión, desde el punto de vista del derecho constitucional y de la teoría del estado, este ha sido el fenómeno más revolucionario de los acontecidos durante la crisis. Por primera vez, el Estado ha dirigido conscientemente una política destinada a reducir la capacidad adquisitiva de sus ciudadanos, sea con una corte directo de los emolumentos en los empleados públicos, sea con reformas laborales

${ }^{6}$ Ben S. Bernanke, The Crisis and the Policy Response (Speech at the Stamp Lecture, London School of Economics, 13 de enero de 2009), disponible en $<$ https://www.federalreserve.gov/newsevents/speech/bernanke20090113a.htm>, visitada el 22 de mayo de 2016.

2 JOURNAL OF INSTITUTIONAL STUDIES 1 (2016) 
orientadas a abaratar la contratación y el despido. El precio de la unidad de coste laboral, tal y como eufemísticamente se ha llamado a este proceso, se ha convertido en el único espacio donde el poder público puede intervenir con celeridad para asegurar, se dice, la competitividad del Estado ${ }^{7}$.

A la luz del derecho constitucional, el Estado deja de ser garante del equilibrio de fuerzas en el proceso productivo, para convertirse en un actor directo de su reordenación. Se produce una traslación de la acomodación de intereses desde la negociación colectiva al legislador. Obviamente, no hay en este corrimiento ningún hecho inconstitucional, pero no deja de ser relevante que se abandone la vía articulada por la Constitución de manera ordinaria para este tipo de conflicto, recurriendo a la intervención legislativa, que tradicionalmente había sido subsidiaria.

\subsection{La politización de la Unión Europea}

La Unión ha tenido desde sus orígenes aversión por el conflicto, por el juego de mayorías y minorías, en tanto que una dialéctica de esa naturaleza, en un proceso de integración entre Estados, padecería el riesgo de aislar a uno o varios de ellos. Se entiende así que la toma de decisiones se haya caracterizado históricamente por la intervención de autoridades independientes responsables de llevar a término los objetivos de los Tratados (la Comisión, el $\mathrm{BCE}$ ), o por procesos dirigidos a labrar consensos. Hoy, el procedimiento legislativo ordinario sigue esta senda, configurado para lograr un acuerdo amplio entre los actores políticos en juego, pero también entre los destinatarios de la norma ${ }^{8}$.

\footnotetext{
7 Para una excelente descripción de este fenómeno y su crisis, Gonzalo Maestro Buelga, Globalización y Constitución débil, TEORÍA y REALIDAD CONSTITUCIONAL, No. 7, 2001.

${ }^{8}$ El rediseño institucional de la Unión es una cuestión pendiente casi desde el Tratado de Ámsterdam y que ahora se ha vuelto acuciante. No obstante, los paradigmas centrales siguen siendo dominantes en el llamado método comunitario, bajo la ilusión de que productor y destinatario pueden confluir en la definición de la norma, véase por todos COMISSIÓN EUROPEA, LIBRO BLANCO SOBRE LA GOBERNANZA (428 final, 2001). Qué duda cabe de que la fuerza de los hechos ha abierto paso franco al reforzamiento del intergubernamentalismo como una manifestación más del nuevo relieve de los Estados, véase José Martín y Pérez de Nanclares, La posición de los Estados Miembros ante la evolución de la Unión Europea: comprometidos con el proceso de integración, convencidos de la necesidad de reforzar los rasgos de intergubernamentalidad, REVISTA DE DERECHO COMUNITARIO EUROPEO, No. 50, 2015.
}

2 JOURNAL OF INSTITUTIONAL STUDIES 1 (2016) 
Las circunstancias han cambiado a partir de la solución europea a la crisis de liquidez y solvencia, que básicamente ha consistido en una masiva y condicionada transferencia de ingresos hacia los Estados en crisis, que no ha procedido de la Unión, sino directamente del presupuesto de otros Estados miembros. Sin duda, este modo de afrontar la cuestión ha provocado por primera vez en la historia del proceso de integración europea un conflicto evidente, situación para la que no parece que se disponga de mecanismos suficientes de ordenación.

Así, de un lado nos encontramos a los Estados miembros que han recibido las ayudas condicionadas, consistentes en una precisa delimitación de su política económica a cambio de recibir los fondos a los que no pueden llegar por las vías del mercado. Pesa sobre ellos una retórica de la austeridad que culpa a sus gobiernos y a sus sociedades de realizar un gasto desproporcionado. Y experimentan la praxis de la austeridad a través de unos memoranda de entendimiento cuyo detalle va directo a cortar el gasto social. Es innegable que en estas sociedades se extienda el rechazo a una serie de decisiones que se consideran de facto externas a su proceso político y causantes de una pérdida de bienestar.

También en los Estados que han llevado la carga de la transferencia de recursos, se ha expandido un malestar difuso. La posibilidad de fijar la política europea, sobre todo en el caso alemán, ha venido acompañada de un intenso debate en torno a las posibilidades que ofrece su Constitución para acometer esas acciones. Especialmente ante el riesgo de que su proceso político se vacíe por mor de la cuantía de las obligaciones financieras asumidas; o bien porque la Unión deje de ser una organización internacional en la que cada Estado responde de su política presupuestaria, para convertirse en un Estado federal donde mutualizan ingresos y, sobre todo, gastos, supuesto para el que la Ley fundamental alemana no ofrece premisas normativas suficientes ${ }^{9}$.

\subsection{La (parcial) despolitización del Estado}

En razón de la crisis, pero también más allá de ella, el proceso de integración europea ha despolitizado la dirección de la económica estatal, en un giro que corre en paralelo a la irrupción del conflicto en el ámbito de la Unión. El Estado constitucional contemporáneo se define por la centralidad del momento electoral, que da forma a la mayoría de gobierno y a la oposición. Esta dialéctica integrativa, prototípica del

9 Por todos, Martin Nettesheim, Wo „endet“ das Grundgesetz? - Verfassungsgebung als grenzüberschreitender Prozess, 51 DER STAAT 3, 2012.

2 JOURNAL OF INSTITUTIONAL STUDIES 1 (2016) 
principio democrático, se prolonga anualmente en el debate y aprobación del presupuesto, momento en el que el Gobierno constata la fortaleza de su mayoría y la oposición proyecta su distinta visión de las circunstancias $^{10}$.

En los últimos años algunos fenómenos políticos e instituciones jurídicas han puesto en solfa esta raíz constitucional. Basta pensar en las crisis de gobernabilidad en Grecia e Italia, que se saldaron provisionalmente extramuros del Parlamento, pero sobre todo al margen del momento electoral. Se recurrió a la figura de los llamados gobiernos técnicos, auspiciados de forma difusa por instituciones internacionales ${ }^{11}$. Y qué decir del particular plebiscito griego, que pese a oponerse a las condiciones de rescate, quedó en agua de borrajas ante la imperiosa necesidad de superar la falta de liquidez bancaria.

Al margen de estos episodios, el dato más relevante fue la institucionalización del semestre europeo, que, como es sabido, se trata de una figura a caballo entre el control jurídico y el político. Los Estados miembros han de satisfacer unas directrices preestablecidas, y la Comisión y el Consejo gestionan con cierto margen de discrecionalidad, su cumplimiento y las consecuencias jurídicas que se han de devengar. Sea como fuere, el semestre europeo ha establecido una dinámica de control sobre los presupuestos estatales, y en su caso sobre el programa estatal de reformas, que hace palidecer la sustancia del debate presupuestario estatal, y en ocasiones un buen pedazo de su política ordinaria.

\section{La crisis de seguridad}

La violencia es un elemento potencialmente intrínseco al poder ${ }^{12}$. Mandar y obedecer, que la voluntad de un sujeto condicione la de otro, remite a menudo, en su dimensión más primaria, a una relación de facto,

${ }^{10}$ Me remito a mi trabajo, Miguel Azpitarte-Sánchez, La funcionalidad de la ley en un sistema politico fragmentado, FUNDAMENTOS, NO. 8: LA METAMORFOSIS DEL ESTADO Y DEL DERECHO (Coord. Miguel Ángel Presno Linera, 2014), en especial p. 261.

${ }^{11}$ Sobre los gobiernos técnicos me vuelvo a remitir al trabajo anterior: Miguel Azpitarte-Sánchez, La funcionalidad de la ley en un sistema político fragmentado, FundAMENTOS, NO. 8: LA METAMORFOSIS DEL ESTADO y DEL DERECHO (Coord. Miguel Ángel Presno Linera, 2014), p. 276 y ss.

12 Existe otra versión del poder, que subraya la importancia de la cooperación, Emily Hauptmann, A local history of "the political", 32 POlitical THeORy 1, 2004. 
en el que la causa de la obediencia es solo la fuerza. No en vano, la historia del derecho constitucional narra los esfuerzos por convertir esa relación de facto en otra jurídica, donde el ejercicio del poder esté ordenado y legitimado por normas.

No le falta razón a la afirmación que fija en el Estado la superación de la guerra civil $^{13}$. Ciertamente, el Estado, y más aún el Estado constitucional, quiere canalizar y regular a través de formas jurídicopolíticas el conflicto social ${ }^{14}$. La negación de la existencia de fuerzas soberanas en su interior y la reconducción de todo uso legítimo de la fuerza a la acción estatal, sometida a derecho, es el gran ingenio que encarna el Estado, y ahí radica su razón de ser ${ }^{15}$.

El 11-s y su trágica progenie en Madrid, Londres, París y Bruselas, por citar solo escenarios europeos, dibuja un nuevo tipo de violencia en el seno del Estado constitucional: es la violencia del $\operatorname{caos}^{16}$. Son varias sus características. Se trata de acciones devastadoras que buscan extender el daño de modo indiscriminado. Carecen de objetivos políticos claros o realizables; es decir, a diferencia de la guerra civil o de la guerra entre Estados, no se persigue provocar un vuelco en las instituciones políticas. Es más bien una violencia de presupuestos culturales que aspira a sembrar entre los ciudadanos del Estado constitucional la sensación de que este es incapaz de ofrecer el primero de los bines públicos: la seguridad. Veamos las consecuencias que conlleva.

${ }^{13}$ Josef Isensee y Paul Kirchhof, Staat und Verfassung, HANDBUCK DES STAATSRECHTS DER BUNDESREPUBLIK DEUTSCHLAND - HDBSTR, Vol. I, (eds., 1994), p. 618.

${ }^{14}$ Cfr. Francisco Balaguer Callejón, Fuentes del Derecho, Vol I: Principios Del ORDENAMIENTO CONSTITUCIONAL (1991), p. 19 y ss.; FRANCISCO BALAGUER CALLEJÓN, FUENTES DEL DERECHO, VOL II: ORDENAMIENTO GENERAL DEL ESTADO Y ORDENAMENTOS AUTONÓMICOS (1992), p. 15 y ss.; Gustavo Zagrebelsky, epílogo, in CONSTANTINO MORTATI, LA CONSTITUCIÓN EN SENTIDO MATERIAL (trad. Almudena Bergarache Gros, 2000), p. 249; igualmente Hermann Huba, Zur Verfassung der Theorie des Pluralismus, DER STAAT, No. 33, 1994.

${ }^{15}$ MARTIN KRIELE, EINFÜHRUNG IN DIE STAATSLEHRE: DIE GESCHICHTLICHE LEGITIMITA"TSGRUNDLAGEN DES DEMOKRATISCHEN VERFASSUNGSSTAATES (5ª ed., 1994), p. 19 y ss.

16 Tempranamente, ANDRÉ GLucKSMAnN, DostoIEVSKI en MANHATTAN (trad. Maíra Cordón, 2002). 


\subsection{La autotutela}

Si el Estado no es capaz de garantizar la seguridad, el ciudadano buscará en el mercado vías alternativas que se ajusten a sus posibilidades. Creo que en Europa estamos todavía muy lejos de algunos escenarios como el norteamericano -y esta es seguramente nuestra última frontera-, en el que la autoprotección marca la pauta del lugar en el que vivimos o de la manera de desplazarnos ${ }^{17}$. Resulta obvio, en cualquier caso, el auge de la de la defensa privada, que se mueve en un doble recorrido: hacia el ciudadano, para satisfacer las necesidades que no llena la acción pública; pero también hacia al Estado, que destila la seguridad pública (incluida la potestad sancionadora) hasta su mínimo irrenunciable, abriéndose de este modo a la cooperación con particulares ${ }^{18}$.

No obstante, la demanda privada de autotutela es probablemente inútil ante el riesgo de terrorismo radical presente en las últimas décadas. Sin embargo, la ineficacia no vacía su sentido, lo que explica que el espacio público se colme de referencias retóricas. Qué duda cabe de que una estación de trenes videovigilada o con presencia masiva de guardias de seguridad, puede transmitirnos una sensación de calma. Pero, en una reacción paralela, tendemos a trazar conexiones puramente simbólicas entre ciertas características y la percepción de una amenaza. Por ejemplo, desde el momento en que el terrorismo invoca ciertas formas de religión, resulta casi inevitable que el temor se active ante algunas maneras de vivir la fe ${ }^{19}$.

${ }^{17}$ Véase en términos generales DAVID GARLAND, THE CULTURE OF CONTROL: CRIME AND SOCIAL ORDER IN CONTEMPORARY SOCIETY (2001), en especial, p. 167 y ss.

18 Para un ilustrativo repaso general del problema, Diego Cámara del Portillo, La privatización del orden público. Las policías privadas, REVISTA DE DERECHO DE LA UNIÓN EUROPEA, No. 7, 2004.

${ }_{19}$ Un ejemplo evidente son los intentos normativos de identificar como un riesgo general el uso por motivos religiosos de vestimentas que cubren íntegramente el rostro, y que ha dado lugar a una intensa discusión constitucional, por ejemplo, en el Tribunal Europeo de Derechos Humanos, S.A.S. v. France, de 1 de julio de 2014 (Application No. 43835/11); en el Tribunal Supremo español, Sentencia de 6 de febrero de 2013, recurso de casación núm. 4118/2011; en el Tribunal Constitucional Federal Alemán, con sus dos sentencias enfrentadas, Claudio Franzius, Vom Kopftuch I zum Kopftuch II. Rückkehr zur Verhältnismäßigkeitsprüfung?, 54 DER STAAT 3, 2015. 


\subsection{La acción estatal preventiva}

El terrorismo ha provocado un cambio en el discurso público. Apenas se discute ya sobre el adecuado nivel de represión y se ha pasado a debatir prioritariamente en torno a las medidas de prevención. Este giro va camino de convertir a la Administración, o al menos a parte de ella, en un nodo de acumulación y gestión de datos. El dato, su tratamiento, es hoy día uno de los más poderosos instrumentos públicos, y en concreto la potestad capital para la prevención y persecución de delitos, en especial los de terrorismo ${ }^{20}$.

Este nuevo contexto a su vez introduce innovaciones sobre la dogmática de los derechos fundamentales ${ }^{21}$. Sin dejar de ser relevante la intervención singular e imperativa, aparecen nuevas injerencias que consisten en la intervención masiva sobre los datos. El tratamiento de datos permite, mediante los algoritmos oportunos, identificar conexiones de conductas acontecidas en el pasado o predeterminar comportamientos futuros. Se necesitan los datos y solo a partir de este instante es factible obtener resultados.

Todavía en el campo de los límites al derecho, el segundo signo distintivo tiene que ver con el carácter desconocido de la intervención, ante la que resulta, por tanto, difícil reaccionar. Ciertamente hay un momento en el que comunicamos nuestros datos personales de manera consciente -cuando cogemos un avión o enviamos un mail-, y aunque sabemos que pueden ser transferidos a la autoridad pública, al momento de su cesión es imposible imaginar todo su potencial. En un gesto que nos parece inocuo, abrimos la puerta al big data, capaz de trazar nuestro pasado y parametrizar nuestro futuro.

En tercer lugar, la relación jurídica que se entabla requiere la cooperación de terceros, por lo general operadores económicos que reciben los datos del consumidor. La típica relación bilateral es ahora trilateral, en la que la ley impone deberes al operador económico, de los

${ }^{20}$ Un importante análisis al respecto José Ángel Brandariz García, ¿Una teleología de la seguridad sin libertad? La difusión de lógicas actuariales y gerenciales en las políticas punitivas, FUNDAMENTOS, NO. 8: LA METAMORFOSIS DEL ESTADO Y DEL DERECHO (coord., Miguel Ángel Presno Linera, 2014), en especial p. 319 y ss.

${ }^{21}$ Me apoyo en parte en las reflexiones de Magdalena Pöschl, La garantía de los estándares de derechos humanos y fundamentales ante las nuevas amenazas que generan los particulares y los actores extranjeros, TEORÍA Y REALIDAD CONSTITUCIONAL, No. 36, 2015. 
que no puede escaparse, pero que a su vez pueden coadyuvar a una vulneración de derecho fundamental.

\subsection{La excepción normalizada y la militarización del discurso político}

En muchas ocasiones, la reacción habitual ante un acontecimiento terrorista consiste en promover reformas legislativas que potencien los instrumentos de investigación y persecución de este tipo de delitos. Tales modificaciones conducen a reforzar las potestades gubernamentales de policía y habilitar mayores limitaciones de derechos fundamentales. Se inspiran, qué duda cabe, en los mecanismos típicos de los estados de excepción, pero acaban prescindiendo de dos de sus elementos distintivos, la temporalidad y la especial justificación. Al introducirlos en la legislación ordinaria se busca consolidarlos en el tiempo, sin que sea necesario recurrir una y otra vez a la motivación y el control singular de los estados de excepción ${ }^{22}$.

Este tipo de reacción anida dos riesgos elementales. El primero consistiría en la banalización de su uso. En tanto que las fuerzas y cuerpos de seguridad del Estado disponen de mecanismos exorbitantes, existe una inclinación comprensible a utilizarlos ante cualquier sospecha, sin apurar las posibilidades de investigación y la correspondiente ponderación de los medios oportunos para proceder a la persecución del delito. Y un segundo riesgo, ligado a este último, es la caída en un acopio meramente simbólico de poderes especiales. Así las cosas, ¿en qué lugar queda el recurso a este tipo de medidas cuando el Estado es incapaz de impedir los actos de terrorismo más dañinos? A nadie se le escapa que la generación de tales potestades sin resultados tangibles, o peor aún, con fracasos evidentes, alimenta la sensación de un Estado incapaz de satisfacer la función elemental de la seguridad.

${ }^{22}$ El discurso de la excepción se ha convertido en un asunto clave dentro de la semántica constitucional (y no solo en lo relativo a los de excepción), véase Massimiliano Guareschi y Federico Rahola, Il sublime dell'eccezione, FundAMENTOS, No. 8: LA METAMORFOSIS DEL ESTADO Y DEL DERECHO (coord. Miguel Ángel Presno Linera, 2014), en especial p. 364 y ss. Desde una perspectiva más amplia, incluyendo la dimensión económica, Enrique Guillén López, La crisis económica y la dirección política: reflexiones sobre los conceptos de necesidad y de elección en la teoría constitucional, REVISTA DE DERECHO CONSTITUCIONAL EUROPEO, No. 20, 2013, disponible en $<$ http://www.ugr.es/ redce/REDCE20/articulos/12 E GUILLEN.htm>, visitado el 23 de mayo de 2016. 
Hay, además, una dimensión más profunda, que tiene que ver con la militarización del discurso político, utilizando términos como "guerra contra el terror" o "enemigo" 23 . Este uso del lenguaje es empujado por una intención evidente de simplificar la realidad, reconduciéndola a un escenario en el que la legitima defensa ante el agresor se convierte en el paraguas de acciones que en otro contexto no podrían presentarse en el discurso político.

El empobrecimiento de la esfera pública a través de un lenguaje militarizado implica además la tentación de descalificar como filo terroristas al disidente político o a los voceros de opiniones alternativas. En este contexto bélico cualquier matización a la acción gubernamental se considera una muestra de tibieza impropia de los tiempos de guerra, o, mucho peor, un acto de cooperación con los terroristas.

\section{La crisis política}

\subsection{Nuevos conflictos, viejos instrumentos}

Antes de nada y con el mero fin de evitar equívocos, conviene intentar una definición del fenómeno de la política ${ }^{24}$. En mi opinión posee dos elementos. En un primer estadio, es el magma de confluencia y contraste de las distintas visiones del mundo y cómo se proyectan socialmente; prima el carácter ideológico y su pluralismo. En un segundo nivel, la política se caracteriza por la relación que los distintos grupos sociales entablan entre sí y, sobre todo, con las instituciones del Estado; destaca el matiz del poder, cómo se accede a él, su modo de ejercicio. En ambos escalones el conflicto se sitúa en el centro del fenómeno político, le da su topografía, y en ella la Constitución ha de jugar un papel clave, ordenando y racionalizando ese conflicto, hasta conducirlo a decisiones estatales que se reconocen como vinculantes para todos.

El constitucionalismo de la segunda mitad del Siglo XX, en el que se incardina el pensamiento de Peter Häberle, se explica de modo

\footnotetext{
${ }^{23}$ No me refiero ahora a las consecuencias jurídico-constitucionales, que ha dado lugar a una amplísima bibliografía, de la que ahora me vale a mero título de ejemplo, PETER BERKOWITZ (ED.), TERRORISM, THE LAWS OF WAR, AND THE CONSTITUTION: DEBATING THE ENEMY COMBATANT CASES (2005).

${ }^{24}$ Repito, con el mero fin de evitar equívocos, pues no está en mi ánimo contribuir a este debate histórico, que empieza, bien es sabido, con el intento de Sócrates de refutar a Trasímaco y su alegato del gobierno del más fuerte, Platón, La República, DiáloGOS, II (trad. Conrado Eggers Lan, 2011), p. 32 y ss.
} 
fundamental por el conflicto que quiere ordenar tras la Segunda Guerra Mundial. Están vivos los rescoldos de la alternativa radical que formuló el periodo de entreguerras - ¿Estado de derecho o dictadura?25- y la Constitución normativa pretende marcar el terreno de juego, dando cabida al pluralismo social ( $\mathrm{y}$, también, expulsando a ciertas posiciones nazismo, comunismo) y facilitando su inserción en las instituciones del Estado, pero sin menoscabar la actuación de este como un ente unitario.

La clave en la articulación del conflicto, de su neutralización, pasa necesariamente por el concepto de libertad política que construye el constitucionalismo de postguerra ${ }^{26}$. Bien es sabido que arranca transformando el modelo del Estado liberal, en cuanto que no basta con un conglomerado de derechos que aseguren un espacio de inmunidad frente al poder, sino que se hace precisa la intervención tuitiva del Estado para dar efectividad a la libertad y la igualdad. La desigualdad (si se quiere la diferencia de clases) será durante mucho tiempo la tensión que active la respuesta constitucional; y el Estado social y sus instrumentos jurídicos el paradigma dominante.

Ahora me interesa apuntar cómo este tipo de conflicto y su correlativo concepto de libertad han ido difuminándose en la definición de la realidad política. No quiero decir con esto que la desigualdad haya dejado de ser una cuestión relevante, pero desde luego es obvio que hasta la irrupción de la crisis fue declinando entre las preocupaciones esenciales. La propia dinámica del Estado social creó una textura bien distinta a la que emergió tras la guerra, hasta el punto de que hablar de clases o de lucha de clases en nada describe una realidad donde la situación profesional no revela un determinado estatus político-colectivo.

La puntilla definitiva a la igualdad como rasgo particular del fenómeno de la política se alcanza tras la caída del muro y la llegada de la llamada "gran moderación". El primer acontecimiento, se ha subrayado infinidad de veces, supone la victoria ideológica del capitalismo, que encontrará campo abierto para experimentar nuevas versiones que giran en torno a la libre circulación de capitales. El segundo hecho es la constatación práctica del éxito ideológico, generando

${ }^{25}$ Hermann Heller, ¿Estado de Derecho o dictadura?, en su libro HERMANN HeLLER, ESCRITOS POLÍTICOS (1985). Sin olvidar el importante prólogo a este libro, Antonio López Pina, Fascismo o Democracia, dilema de Herman Heller, in Hermann Heller, ESCRITOS POLÍTICOS (1985).

${ }_{26}$ Me remito a mi trabajo, Miguel Azpitarte-Sánchez, Konrad Hesse en el siglo XXI, in Konrad Hesse, Escritos de Derecho Constitucional (ed., Pedro Cruz Villalón y Miguel Azpitarte-Sánchez, 2011), en especial p. 279. 
sociedades que se mueven cerca del pleno empleo y sin apenas inflación. El objetivo del siglo parecía haberse conseguido; la neutralización del conflicto había sido un éxito.

En paralelo a ese logro, en la sociedad y su política va germinando un nuevo tipo de conflicto primario, que tiene que ver con la definición y exposición en el espacio público de la identidad personal, en especial aquellos rasgos que se consideran inamovibles y fuera del estándar ${ }^{27}$. La raza, el género, la orientación sexual crean un nuevo discurso sobre la igualdad que tiene concomitancias obvias con el problema anterior de la igualdad material, pero que pronto cobrará su propia lógica. No es tan importante una acción estatal, sobre todo legislativa y ejecutiva, dirigida a disolver las diferencias materiales, sino que prima una actividad jurisdiccional destinada a garantizar que las características identitarias no conllevan tratos peyorativos. Se consolida un constitucionalismo en el que dominan los derechos fundamentales. Y aunque este conflicto y su correlativo concepto de libertad siguen presentes en nuestros días, no hay duda de que las dos crisis descritas en los epígrafes anteriores han socavado su importancia, en tanto que las respuestas que han generado son inútiles para esas dificultades.

En definitiva, la tesis principal de este tercer apartado consiste en destacar que nos encontramos en un momento en el que se han desvanecido los conflictos y el concepto de libertad (y con ellos el de política) sobre los que se había construido el constitucionalismo de postguerra. Esta circunstancia es ya en sí un importante dilema, pues nos interroga sobre la capacidad de nuestros instrumentos constitucionales para dar cauce y racionalizar las nuevas tensiones. Ocurre, sin embargo, que la situación se hace todavía más compleja en tanto que no es posible, o por lo menos no lo es para mí, identificar cuál es la nueva topografía de la política, esto es, los conflictos esenciales que la definen, y la idea de libertad que ha de darles respuesta.

\subsection{En busca del conflicto contemporáneo}

${ }^{27}$ La descripción de este fenómeno, ceñida a los EE.UU. pero perfectamente traspasable a cualquier sociedad occidental lo encontramos en RICHARD RORTY, ACHIEVING OUR COUNTRY: LEFTIST THOUGHT IN TWENTIETH-CENTURY AMERICA (1998). Y este fenómeno se traslada fácilmente al campo jurídico a través de la teoría de la jurisdicción formulada por JOHN HART ELY, DEMOCRACY AND DISTRUT: A THEORY OF JUDICIAL REVIEW (1980). 
Siempre de un modo tentativo, me atrevo a señalar que son tres las líneas de tensión que dominan las sociedades europeas contemporáneas -el choque entre la vieja y nueva política; la austeridad; y la reconfiguración del demos. Antes de aventurar algunas ideas sobre cada una de ellas, me gustaría subrayar que en todas ellas sobresale su naturaleza moral antes que política. Quiero decir con esto que su matriz, su punto de partida, es una concepción de lo justo, de lo bueno, que ha de condicionar la praxis política y, en su caso, la acción del Estado.

Qué duda cabe de que en el constitucionalismo de postguerra también había un componente moral, una idea de justicia, tal y como reflejaba la inclusión de valores en las Constituciones o el uso de sus derechos fundamentales como principios objetivos llamados a una aplicación de máximos. Y también es cierto que las fuerzas políticas en liza construían su discurso con mayores o menores apelaciones a la justicia. Pero la verdad es que los sistemas constitucionales formulaban un dique frente a cualquier pretensión de imponer una concepción moral - de nuevo los derechos fundamentales-. De este modo, la finalidad de la actuación estatal, su utilización racional para alcanzar determinados fines, se convertía en el eje dominante.

En los nuevos conflictos, su raíz moral fija como objetivo no tanto la actuación del Estado, su fuerza transformadora, sino la recomposición de la sociedad. Mientras que en el constitucionalismo de postguerra la ordenación de los conflictos pasaba por una actuación estatal que aspiraba a reforzar la autonomía del individuo, los nuevos conflictos religan el individuo a una idea de bien colectivo, de suerte que se espera de ellos una comunión con los principios de justicia.

Está vocación moral de las actuales líneas divisorias empuja hacia una consecuencia práctica similar, que no es otra que la superación de la democracia representativa, bien por métodos que refieren a la independencia técnica, bien por la reivindicación de la democracia plebiscitaria. En definitiva, los conflictos contemporáneos abandonan la dicotomía mayoría de gobierno-oposición que ha tenido un lugar central en el constitucionalismo de postguerra y buscan técnicas políticojurídicas alternativas.

\section{a. Lo nuevo frente a lo viejo: de América a Europa}

La irrupción del llamado Tea Party en los Estados Unidos acabó por dar cuerpo a un movimiento político que llega hasta nuestros días con el vigor inusitado que representa la candidatura de Donald Trump a la Presidencia. La esencia de esta corriente, su principio aglutinador, consiste en un discurso cuyo paradigma radica en la crítica al sistema 
político imperante, en especial a su clase política. Se invita a que la persona común reaccione y desaloje a aquellos que han hecho del ejercicio del poder su profesión, olvidándose de los problemas que de verdad preocupan a la sociedad.

Se construye así una propuesta caracterizada por tres rasgos. El fin de la dicotomía izquierda-derecha cómo lógica explicativa de las diferencias políticas. Una retórica pretendidamente democrática en cuanto que subraya la importancia de la persona común frente a la oligarquía. Y un sustrato de pureza moral que contrasta con la clase dominante, a la que en general se considera corrupta; sustrato que se sitúa en las raíces religiosas, o en el ideal capitalista del hombre hecho a sí mismo (Trump).

La configuración de este tipo de conflicto -lo nuevo frente a lo viejo-, teniendo su origen en los Estados Unidos, ha logrado con patrones similares éxitos rotundos en Latinoamérica. Allí, la función purificadora de la religión o del hombre hecho a sí mismo, ha sido sustituida por la invocación de lo militar, presente en líderes como Chavez o Humala, o por la referencia indigenista, característica que han destacado en prácticamente todos los países (al margen, el kirchnerismo, basado todavía en el factor peronista). En cualquier caso, la experiencia latinoamericana es importante en tanto que las nuevas fuerzas políticas han conseguido acceder al poder y en su ejercicio hemos visto una clara inclinación a practicar dinámicas que superan las propias de la democracia representativa. Esto ha sido una consecuencia en parte del contexto de sistemas presidencialistas, pero también de la voluntad de privilegiar los mecanismos de democracia directa (por ejemplo, los referéndum revocatorios de los cargos públicos) y, sobre todo, de la activación del poder constituyente, instrumento ideal para resolver el conflicto esencial de lo nuevo frente a lo viejo, y partir de cero.

El fenómeno ya está presente en Europa. De un lado ha servido para que los viejos partidos de ultraderecha salgan del ostracismo. Y de otro, observamos la irrupción de fuerzas políticas -el Movimiento Cinco Estrellas en Italia, Podemos en España y, en Alemania, Alternativa para Alemania o el Partido Pirata. Se trata de grupos que, al margen de su programa, se definen en esencia por una crítica global frente al "sistema" o la "casta".

\section{b. La austeridad: un conflicto europeo}

La crisis económica y los mecanismos que en el seno de la Unión se han previsto para afrontar las dificultades recientes, han situado en el centro del escenario el paradigma de la austeridad. Esta idea tiene una verbalización sencilla: cada Estado debe ser responsable de sus cuentas y 
no gastar por encima de lo posible; si los ingresos propios no llegan y el mercado renuncia a financiar al Estado, entonces la ayuda de los restantes Estados miembros ha de ser condicionada al cumplimiento de los criterios de reducción del gasto, aumento de la presión tributaria y reforma del mercado de trabajo ${ }^{28}$.

Esta nueva línea de tensión rompe también con la división tradicional izquierda-derecha; el partido con la responsabilidad de gobierno, sea del color que sea, acaba asumiendo las premisas de la austeridad, tal y como ha ejemplificado el Ejecutivo de Syriza en Grecia. La austeridad, además, posee igualmente un matiz moral, que en esta ocasión se hace evidente en los términos lingüísticos, que siendo novedosos en el campo de la política, sin embargo son habituales en los asuntos de ética ${ }^{29}$. Finalmente, la austeridad también asume una relación directa con el principio democrático, por más que sea un tanto compleja. Aunque habitualmente y con razón se aduce que las medidas de rescate se dictan al margen de las instancias parlamentarias de los Estados afectados, al mismo tiempo aquellos países que han liderado los rescates, principalmente Alemania, han pretendido dotar a la austeridad de un fundamento democrático. En tanto que la habilitación de gasto es una decisión nuclear del Parlamento nacional, la transferencia de ingresos masivos y la asunción de obligaciones por un largo periodo de tiempo pueden acabar vaciando la naturaleza democrática del Estado.

No obstante, cabe señalar, al igual que en el conflicto anterior, que la articulación de la austeridad se realiza al margen e incluso contra la dinámica de la democracia representativa. Como ya se ha señalado, basta con recordar los gobiernos técnicos en Italia o Grecia. Fueron supuestos en los que la crisis de gobernabilidad se resolvió extramuros de la sede parlamentaria y desplazando al momento electoral como vértice de las democracias constitucionales. Los gobiernos técnicos se instauraron por su compromiso con la austeridad y una vez que recibieron el refrendo informal de las instancias internacionales. Más aún, el llamado "semestre europeo", esa suerte de control híbrido entre lo jurídico y lo político de la económica estatal, termina por diluir la importancia política del debate

${ }^{28}$ La bibliografía sobre este aspecto es amplia, ahora me basta, respecto a la condicionalidad que empuja hacia la austeridad el ensayo que va del detalle a la visión de conjunto, de Manuel López Escudero, La nueva gobernanza económica de la Unión Europea: ¿una auténtica unión económica en formación?, REVISTA DE DERECHO COMUNITARIO EUROPEO, No. 50, 2015, en especial p. 39 y ss.

${ }^{29}$ Podría sostenerse que en origen ética y economía fueron juntas, MAX WEBER, LA ÉTICA PROTESTANTE Y EL “ESPÍRITU” DEL CAPITALISMO (trad. Joaquím Abellán, 2001). 
presupuestario, instante clave en las democracias constitucionales ${ }^{30}$.

Un segundo instrumento para articular y racionalizar el conflicto derivado de la austeridad ha sido la reforma de las Constituciones impulsadas por el derecho de la Unión. La conversión de un paradigma político-moral en norma constitucional pretende en definitiva cerrar el debate y con él las disidencias que puedan surgir en torno a las premisas $\mathrm{y}$ consecuencias de este criterio $^{31}$. Se le quiere dar, por tanto, una determinada operatividad jurídica, con la aspiración de que la austeridad, precisamente por su basamento moral, acabe penetrando en el funcionamiento cotidiano de la sociedad.

\section{c. La redefinición del demos: un conflicto clásico}

Toda comunidad política, implícita o explícitamente, está en constante delimitación, buscando las fronteras que marcan la línea de inclusión y estipulando los fines que han de orientar su acción. En la última década, Europa está experimentando una sucesión de acontecimientos que sitúan la cuestión en el centro de la palestra.

Nos encontramos, sin duda, con el conflicto clásico de entes que con una definición territorial y política clara -Escocia y Cataluña- pretenden erigirse en un Estado independiente. Las viejas cuestiones de la soberanía vuelven a cobrar interés.

Pero la configuración del demos encuentra hoy en el seno de la Unión Europea un nuevo tipo de formulación que afecta a todos los Estados Miembros. Se hizo evidente en el fracasado Tratado constitucional (quizá por ello no llegó a buen puerto), que exigió de todos los Estados una decisión clara sobre su naturaleza como sujeto político. Recientemente, sin embargo, brotan dos nuevas expresiones del mismo problema. El llamado Brexit, que mediante un referéndum quiere delimitar la integración del Reino Unido, apuntalando barreras que aspiran a cerrar del demos. Y el intenso debate alemán sobre la resistencia de su Constitución ante los nuevos pasos de integración que puedan sucederse, sobre todo si se encaminan hacia una Europa de corte federal, para lo que

\footnotetext{
${ }^{30}$ Para un desarrollo de estos argumentos remito a mi trabajo, Miguel AzpitarteSánchez, Los confines de la democracia y la solidaridad: A propósito de las decisiones del Tribunal Constitucional Federal Alemán de 14 de enero y 18 de marzo de 2014 que enjuician el marco jurídico supranacional de las políticas de rescate, REVISTA ESPAÑOLA DE DERECHO CONSTITUCIONAL, No. 101, 2014, en especial p. 317 y ss.

${ }^{31}$ Para una revisión comparada y en contexto con otras reformas, Sabrina Ragone, Constitutional Effects of the financial crisis at European and National level: a comparative overview, Revista GENERAl De DeReChO Público COMPARADO, No. 15, 2014.
} 
sería necesario, según la doctrina alemana, una reforma de la Constitución de acuerdo con lo dispuesto en el artículo 146 de la Ley Fundamental, que requiere un referéndum.

Lo significativo es que este tipo de conflicto en torno a la naturaleza de la comunidad política posee unas líneas directrices que coinciden asimismo con los conflictos antes descritos. En primer lugar, como cualquier debate constituyente, supera la tradicional separación izquierda-derecha; esta última cobra sentido en el juego de la dinámica ordinaria y se trasciende cuando el dilema consiste en fijar las bases de la comunidad política $^{32}$. En segundo lugar, aunque sea incorrecto sostener que este tipo de debates tienen un trasfondo moral, no es menos cierto, sin embargo, que son discusiones prepolíticas, puesto que señalan los linderos en los que va a ser posible la libertad y el modo esencial en el que se va a entablar la relación entre los individuos y estos con el Estado. No es una discusión sobre fines alternativos, sino sobre las propias condiciones que hacen posible la discusión sobre fines y las personas llamadas a participar en ese debate. Finalmente, en tercer lugar, es indiscutible cómo en este conflicto vuelven a reventarse las costuras de la democracia representativa en favor de la plebiscitaria. Es común que en todo procedimiento de reforma o constituyente, el referéndum esté llamado a cerrar el debate con un efecto ratificatorio sobre lo discutido en una sede de corte parlamentario (opera como una institución de control). Sin embargo, en la fisonomía de los cuatro debates antes señalados, el referéndum se convierte en el instrumento clave para la resolución del conflicto, que acaba planteándose en términos binarios y de extrema simplificación. No antecede o culmina un debate bajo las premisas de la comunicación racional, sino que aspira a sustituirlo, lo que evidentemente conlleva cualificadas consecuencias sobre la propia configuración de la identidad política (funciona como una institución decisoria).

32 Por todos, Horst Ehmke, quien ya en la segunda mitad del siglo abre una nueva senda cuando presenta al soberano como un ente plural, como un espacio de mayorías y minorías que se unifica en el momento constituyente, Horst Ehmke, Grenzen der Verfassungsänderung, in HORST EHMKE, BEITRÄGE ZUR VERFASSUNGSTHEORIE UND VERFASSUNGSPOLITIK (ed., Peter Häberle, 1981), p. 89 y ss. 


\section{La Utilidad del Pensamiento de Peter Häberle ante el} ESCENARIO CONTEMPORÁNEO: UNA GUÍA dE TRABAJO

En las páginas que siguen, apoyándome en el pensamiento de Peter Häberle, querría hacer una suerte de índice, en el que quedasen marcados los hitos que han de guiar la reflexión constitucional en torno al contexto antes descrito.

\section{El pluralismo como premisa ${ }^{33}$}

La Constitución es una norma jurídica, cuya aplicación resuelve controversias. Sin embargo, fuera del mundo de los juristas, es un texto que vuelca la autorrepresentación de sus destinatarios. Los ciudadanos proyectan su experiencia personal, sus anhelos y esperanzas en la lectura de la norma suprema; hacen de la Constitución un fenómeno cultural.

En estas circunstancias, la realidad constitucional solo puede ser plural. Cada persona posee potencialmente una comprensión de la Constitución; pero, además, aprovecha el marco que esta le ofrece para construirse su propia configuración de la realidad. Me parece, por tanto, que la obra de Peter Häberle, también en estos tiempos, empuja a hacer del pluralismo el criterio material desde el que abordar el contexto contemporáneo. Cualquier paso que vaya en dirección contraria cobrará una mirada imperfecta, seguramente al estar condicionada por alguna precomprensión ideológica que remarca aspectos del texto normativo, olvidando que abre una realidad múltiple, fruto de las diversas miradas que la iluminan.

La centralidad del pluralismo a resultas de la experiencia cultural que supone toda Constitución provoca dos consecuencias. La primera tiene que ver con el carácter poliédrico de la libertad. Es inútil pensar que la libertad es solo económica, política, de pensamiento, etc. Según el contexto primará uno u otro matiz, destacando siempre la capacidad del ser humano para configurar su entorno y actuar en conformidad con esas premisas. Por ejemplo, en un contexto de crisis económica, es comprensible que se subraye la necesidad de que el Estado cree las condiciones necesarias para el desarrollo de una vida digna; o, en un ámbito de diversidad religiosa, se entiende que sea este tipo de libertad

\footnotetext{
${ }^{33}$ Este epígrafe se apoyaría en los argumentos expuestos por el profesor Häberle en los epígrafes IV, V y VII de su texto, Peter Häberle, Ein wissenschaftlicher Rückblick, REVISTA EstUdOS INSTITUCIONAIS, Vol. 2, 1, 2016.
}

2 JOURNAL OF INSTITUTIONAL STUDIES 1 (2016) 
la que domine la lectura del texto constitucional.

La segunda consecuencia derivada del pluralismo supone aceptar que toda realidad constitucional es necesariamente conflictiva. Sin duda, una de las funciones primordiales de la Constitución es ordenar y racionalizar el pluralismo, evitando así que derive en una tensión insuperable. Pero no es menos verdad que la Constitución fomenta ese pluralismo, aceptando que en el espacio público se enfrentaran distintas visiones, cuya convivencia será delimitada por el texto constitucional, que evita que alguna de ellas se convierta en absoluta.

\section{Sobre la función de la Constitución estatal ${ }^{34}$}

Häberle nos indicó hace ya mucho tiempo que las normas supremas estatales se habían convertido en Constituciones parciales, puesto que toda la realidad política ya no podía explicarse a partir de ellas, sino que necesitaba el complemento imprescindible del derecho de la Unión. Esta constatación, que hoy aceptamos como una premisa insoslayable, a la vez impone un interrogante capital: si la Constitución tradicionalmente la hemos comprendido a partir de su capacidad para dotar de unidad a la realidad política, ¿cuál es hoy su función?

Entiendo que la Constitución todavía ha de cumplir la tarea de dar forma a un grupo humano que se hace presente como sujeto político al dotarse de una norma suprema, que a la vez sienta las bases para su continuidad en el tiempo. Pero este sujeto político, este demos unificado por la Constitución, ya no se explica por su relación antagónica frente a otro sujetos políticos, sino por su relación coordinada con ellos $\mathrm{y}$, especialmente, por su vínculo con el proceso de integración. Tal circunstancia hace que la Constitución, precisamente por ser parcial en la ordenación de la realidad, cobre ahora la función adicional de dar sentido a esa parcialidad, y abrir los canales para que la confluencia de realidades constitucionales sea racional.

De este modo, si durante la segunda mitad del siglo XX el gran dilema del derecho constitucional, al que Häberle dedico gran parte de su obra, no fue otro sino la tensión entre Constitución y tiempo, ahora emerge en paralelo otro asunto capital, a saber, la tensión entre Constitución y espacio. En efecto, muchas de nuestras instituciones constitucionales -la

${ }^{34}$ Este epígrafe dialogaría con los epígrafes XI, X, XI, XII del texto del profesor Häberle, Peter Häberle, Ein wissenschaftlicher Rückblick, REVISTA ESTUDOS InSTITUCIONAIS, Vol. 2, 1, 2016.

2 JOURNAL OF INSTITUTIONAL STUDIES 1 (2016) 
reforma, la interpretación, la legislación- se explican como instrumentos que permiten sostener la normatividad de la Constitución ante la realidad cambiante. La adaptan y de este modo se logra que las generaciones presentes encuentren en la norma suprema el presupuesto de legitimidad del sistema político y del ordenamiento jurídico. Hoy, sin embargo, el demos no solo cambia por el paso del tiempo, sino que también recibe el impacto de otras discursos constitucionales que sin estar generados en ese mismo demos, lo condicionan $u$ ofrecen a sus ciudadanos experiencias que se convierten en anhelos posibles. En Europa llevamos décadas explorando si los instrumentos tradicionales ya citados, como la reforma o la interpretación, son útiles para que la Constitución cumpla esta nueva función. Y, sobre todo, se trata de elaborar una dogmática que permita añadir herramientas a esta tarea. No cabe duda de que las tesis häberlianas sobre el quinto método interpretativo o la evolución de los textos normativos son ejemplos en esta dirección.

\section{Sobre la función constitucional del derecho de la Unión ${ }^{35}$}

El tramo final de la obra de Peter Häberle ha estado encaminado a buscarle un sentido constitucional a la Unión Europea. Basta recordar su célebre concepto "derecho constitucional común europeo", que aún hoy tiene gran utilidad para comprender muchos fenómenos derivados del proceso de integración. Pero más que nunca, seguimos explorando caminos normativos y dogmáticos que ofrezcan una razón constitucional a la Unión, esto es, premisas que permitan ver en sus textos normativos criterios que legitiman el ejercicio del poder.

En este sentido, la Unión ha encadenado dos grandes fracasos -la no aprobación del Tratado Constitucional y la insatisfactoria solución a la crisis - que nos sirven al menos para descartar provisionalmente vías que pudiesen dar luz constitucional a la Unión. De un lado, ambas decepciones creo que empujan a abandonar, siquiera a medio plazo, la idea de que la Unión construya una unidad política comparable a la de los Estados. No parece que se espere a un pueblo europeo capaz de dotarse de una. Basta con ciudadanos estatales que articulan su participación política en el Estado; no en vano, las medidas arbitradas durante la crisis han pasado precisamente por reforzar la responsabilidad del sistema político estatal. De otro lado, la crisis económica ha puesto

35 Este epígrafe se aprovecha de lo dispuesto por el profesor Häberle en los epígrafes I, II, III y XII, Peter Häberle, Ein wissenschaftlicher Rückblick, REVISTA ESTUDOS INSTITUCIONAIS, Vol. 2, 1, 2016. 
coto a la explicación clásica, que veía en la Unión un instrumento para racionalizar los excesos proteccionistas del Estado. Es importante señalar, que bajo esta premisa el mercado interior se había convertido durante décadas en el polo de atracción de los distintos conflictos, que se canalizaban a través de la aplicación de las libertades fundamentales. Con ellas, los ciudadanos ponían en cuestión medidas estatales que consideraban un obstáculo a la libre circulación de factores productivos, pero en algunas ocasiones, aunque fuese con el paso cambiado, abrían importantes debates de naturaleza constitucional, en tanto que formulaban límites al Estado para incidir en la sociedad. Esa capacidad de reivindicar derechos subjetivos fundados en los Tratados, incluso frente al legislador estatal, acabó por convertirse en la divisa del constitucionalismo de la Unión.

Si esta vía ha perdido pregnancia, es preciso preguntarse cómo se puede volver a dotar de sentido constitucional a la Unión. Todas las miradas apuntan, obviamente, a los derechos fundamentales y al papel que el Tribunal de Justicia quiera darles, asunto en el que todavía está titubeando respecto a la salida oportuna. Y es aquí, de nuevo, donde el pensamiento de Peter Häberle puede ser iluminador. Recordemos que en sus orígenes la Ley Fundamental Alemana no se consideraba una Constitución, sino una mera solución provisional hasta la reunificación de Alemania. De alguna forma, el canal clásico de legitimidad democrática -el poder constituyente- estaba obturado, de ahí que la sociedad y la dogmática alemana buscasen otra salida. Ese camino lo ofrecieron los derechos fundamentales, y en su comprensión Häberle desempeñó un papel capital desde el momento que propuso remodelar su dogmática, abriéndolos a desempeñar funciones adicionales, más allá de la mera protección de ámbitos subjetivos.

Los derechos fundamentales sirvieron para perfeccionar una norma suprema que en sus inicios no se consideraba Constitución. Este hilo debería conducirnos a reflexionar sobre la oportunidad de un uso de los derechos fundamentales de la Unión de tal modo que sean el nuevo referente normativo que vehicule el conflicto, completando la función que hasta ahora han venido desempeñando las libertades fundamentales. Si a través de estas la Unión construyó un espacio público de los intérpretes con motivaciones económicas, el uso inteligente de los derechos fundamentales podría conducir a un espacio público de los intérpretes constitucionales. 


\section{Los fines del Estado ${ }^{36}$}

Resulta difícil imaginar un Estado que no esté empeñado, al menos desde el punto de vista normativo, en la procura de bienes y servicios esenciales, sea prestándolos por sí mismos, sea controlando su dación por los agentes del mercado. Es obvio que la hipótesis de un Estado que abdique de estas responsabilidades sería el fin de una época. Pero también es cierto que la elección de cuáles han de ser esos servicios esenciales y el modo de atenderlos compondrá siempre un debate interminable, pues implica la determinación específica de la naturaleza del Estado y del mercado.

Me parece, no obstante, que la clave de los años venideros pasa por resituar este problema en un contexto más amplio, de manera que el dilema ya no es tanto Estado versus mercado, sino Estados versus globalización financiera. Si hace algunas décadas, un Estado todavía podía plantearse incidir de modo efectivo sobre la dinámica de su mercado y propiciar lógicas redistributivas, hoy este tipo de actuación se hace cada vez más difícil. La libre circulación de capitales permite una reacción inmediata de los inversores ante regulaciones que consideran adversas; así, aunque una decisión estatal esté llena de bondad, a corto o medio plazo puede llevar a una huida de capitales con graves consecuencias para la estabilidad económica.

La dependencia del Estado de un capital de movilidad ilimitada, en mi opinión sitúa en el centro del debate la necesidad de reformular el principio de solidaridad. Tradicionalmente este principio estaba íntimamente ligado a la naturaleza del demos: la redistribución de la riqueza se consideraba posible solo entre los integrantes de un pueblo, en el entendido de existían unos ligámenes culturales o sociológicos con base suficiente para aceptar este tipo de transferencia. La idea de un destino común justificaba la solidaridad.

Sin embargo, esta perspectiva intraestatal es insuficiente para abordar los problemas contemporáneos, que reclaman la construcción política y dogmática de un principio de solidaridad interestatal o supraestatal (con su correspondiente poder tributario propio). El camino pasa por aceptar como un problema político innegable que las actuaciones económicas de un Estado -sobre todo si comparten la moneda-, afectan irremediablemente a otro. Y, sobre todo, es inevitable dar por hecho que la riqueza de un país dentro de la unión monetaria es en parte resultado

${ }^{36}$ En especial véase el epígrafe XI del texto del profesor Häberle, Peter Häberle, Ein wissenschaftlicher Rückblick, REvisTA EsTUDOS INSTITUCIONAIS, Vol. 2, 1, 2016.

2 JOURNAL OF INSTITUTIONAL STUDIES 1 (2016) 
de ese marco común, que genera un destino compartido.

\section{REFERENCIAS}

ANDRÉ GluCKSMANN, DOSTOIEVSKI EN MANHATTAN (trad. Maíra Cordón, 2002).

Andreas Voßkuhle y Thomas Wischmeyer, Der Jurist im Kontext: Peter Häberle zum 80. Geburtstag, JAHRBUCH DES ÖFFENTLICHEN RECHTS DER GEGENWART, No. 63, 2015.

Antonio López Pina, Fascismo o Democracia, dilema de Herman Heller, in HERMANN HELLER, ESCRITOS POLÍTICOS (1985).

Armin Curveys, The Sovereign Debt and EMU crises: A perfect confederal storm?, LEIDEN UNIVERSITY REPOSITORY, 2013.

Ben S. Bernanke, The Crisis and the Policy Response (Speech at the Stamp Lecture, London School of Economics, 13 de enero de 2009), disponible en

$<$ https://www.federalreserve.gov/newsevents/speech/bernanke20090113 a.htm>, visitada el 22 de mayo de 2016.

CARLOS DE CABO MARTíN, LA CRISIS DEL ESTADO SOCIAL (1986).

Claudio Franzius, Vom Kopftuch I zum Kopftuch II. Rückkehr zur Verhältnismäßigkeitsprüfung?, 54 DER STAAT 3, 2015.

COMISSIÓN EUROPEA, LIBRO BLANCO SOBRE LA GOBERNANZA (428 final, 2001).

DAVID GARLAND, THE CULTURE OF CONTROL: CRIME AND SOCIAL ORDER IN CONTEMPORARY SOCIETY (2001). 
David Levi-Faur, Regulation \& Regulatory Governance, JERUSALEM PAPERS IN REgUlATION \& GOVERNANCE, No. 1, 2010.

Diego Cámara del Portillo, La privatización del orden público. Las policías privadas, ReVISTA DE DeRECHO DE LA UnIÓN EUROPEA, No. 7, 2004.

Diego VALAdÉS, CONVERSACIONES ACADÉMICAS CON PETER HÄBERLE (2006), disponible en $<$ http://biblio.juridicas.unam.mx/libros/libro.htm?l=1854 $>$, visitada el 22 de mayo de 2016.

Emily Hauptmann, A local history of "the political", 32 POLITICAL THEORY $1,2004$.

Enrique Guillén López, La crisis económica y la dirección política: reflexiones sobre los conceptos de necesidad y de elección en la teoría constitucional, Revista De DeReCho Constitucional EuROPEO, No. 20, 2013, disponible en

<http://www.ugr.es/ redce/REDCE20/articulos/12 E GUILLEN.htm>, visitado el 23 de mayo de 2016.

Ernst Wolfgang Böckenförde, Die Bedeutung der Unterscheidung von Staat und Gesellschaft im demokratischen Sozialstaat der Gegenwart, RECHT, STAAT, FREIHEIT: STUDIEN ZUR RECHTSPHILOSOPHIE, STAATSTHEORIE UND VERFASSUNGSGESCHICHTE (1991).

Francisco Balaguer Callejón, Fuentes del Derecho, Vol I: PRINCIPIOS DEL ORDENAMIENTO CONSTITUCIONAL (1991).

Francisco Balaguer CALlejón, Fuentes del Derecho, Vol II: ORDENAMIENTO GENERAL DEL ESTADO Y ORDENAMENTOS AUTONÓMICOS (1992). 
Giandomenico Majone, The regulatory state and its legitimacy problems, 22 WEST EUROPEAN POLITICS 1, 1999.

Gonzalo Maestro Buelga, Globalización y Constitución débil, TEORÍA Y REALIDAD CONSTITUCIONAL, No. 7, 2001.

Gustavo Zagrebelsky, epílogo, in CONSTANTINO MORTATI, LA CONSTITUCIÓN EN SENTIDO MATERIAL (trad. Almudena Bergarache Gros, 2000).

Hermann Heller, ¿Estado de Derecho o dictadura?, EscRITOS POLÍTICOS (1985).

Hermann Huba, Zur Verfassung der Theorie des Pluralismus, DeR STAAT, No. 33, 1994.

Horst Ehmke, Grenzen der Verfassungsänderung, in HORST EHMKE, Beiträge ZUR Verfassungstheorie und VerfassungspolitiK (ed., Peter Häberle, 1981).

John HART Ely, DEMOCRACy AND Distrut: A THEORY OF JUDiCiAL REVIEW (1980).

José Ángel Brandariz García, ¿Una teleología de la seguridad sin libertad? La difusión de lógicas actuariales y gerenciales en las políticas punitivas, FUNDAMENTOS, NO. 8: LA METAMORFOSIS DEL ESTADO Y DEL DERECHO (coord., Miguel Ángel Presno Linera, 2014).

José Martín y Pérez de Nanclares, La posición de los Estados Miembros ante la evolución de la Unión Europea: comprometidos con el proceso de integración, convencidos de la necesidad de reforzar los rasgos de intergubernamentalidad, Revista de Derecho Comunitario Europeo, No. 50, 2015. 
Josef Isensee y Paul Kirchhof, Staat und Verfassung, HANDBUCK DES STAATSRECHTS DER BUNDESREPUBLIK DEUTSCHLAND - HDBSTR, Vol. I, (eds., 1994).

Konrad Hesse, Observaciones sobre la actualidad y el alcance de la distinción entre Estado y Sociedad, ESCRITOS DE DERECHO CONSTITUCIONAL (eds. Miguel Azpitarte-Sánchez y Pedro Cruz Villalón, 2011).

Magdalena Pöschl, La garantía de los estándares de derechos humanos $\mathrm{y}$ fundamentales ante las nuevas amenazas que generan los particulares y los actores extranjeros, TEORÍA Y REALIDAD CONSTITUCIONAL, No. 36, 2015.

Manuel García-Pelayo, El Estado Social y sus implicaciones, LAS TRANSFORMACIONES DEL ESTADO CONTEMPORÁNEO (1996).

Manuel López Escudero, La nueva gobernanza económica de la Unión Europea: ¿una auténtica unión económica en formación?, REVISTA DE DERECHO COMUNITARIO EUROPEO, No. 50, 2015.

MARTIN KRIELE, EINFÜHRUNG IN DIE STAATSLEHRE: DIE GESCHICHTLICHE LEGITIMITA"TSGRUNDLAGEN DES DEMOKRATISCHEN VERFASSUNGSSTAATES (5 ${ }^{\mathrm{a}}$ ed., 1994).

Martin Lodge, Regulation, the Regulatory State and European Politics, 31 WEST EUROPEAN POLITICS 1-2, 2008.

Martin Nettesheim, Wo „endet" das Grundgesetz? - Verfassungsgebung als grenzüberschreitender Prozess, 51 DER STAAT 3, 2012.

Massimiliano Guareschi y Federico Rahola, Il sublime dell'eccezione, FUNDAMENTOS, NO. 8: LA METAMORFOSIS DEL ESTADO Y DEL DERECHO (coord. Miguel Ángel Presno Linera, 2014). 
MAX WEBER, LA ÉTICA PROTESTANTE Y EL “ESPíRITU” DEL CAPITALISMO (trad. Joaquím Abellán, 2001).

Miguel Azpitarte-Sánchez, Konrad Hesse en el siglo XXI, in KONRAD Hesse, Escritos de Derecho Constitucional (ed., Pedro Cruz Villalón y Miguel Azpitarte-Sánchez, 2011).

Miguel Azpitarte-Sánchez, La funcionalidad de la ley en un sistema político fragmentado, FUNDAMENTOS, NO. 8: LA METAMORFOSIS DEL ESTADO Y DEL DERECHO (Coord. Miguel Ángel Presno Linera, 2014).

Miguel Azpitarte-Sánchez, Los confines de la democracia y la solidaridad: A propósito de las decisiones del Tribunal Constitucional Federal Alemán de 14 de enero y 18 de marzo de 2014 que enjuician el marco jurídico supranacional de las políticas de rescate, REVISTA ESPAÑOLA DE DERECHO CONSTITUCIONAL, No. 101, 2014.

PETER BERKOWITZ (ED.), TERRORISM, THE LAWS OF WAR, AND THE Constitution: Debating the ENEMy Combatant CASEs (2005).

Peter Häberle, Ein wissenschaftlicher Rückblick, 2 REvisTa EsTUDOS INSTITUCIONAIS 1, 2016.

Platón, La República, Diálogos, II (trad. Conrado Eggers Lan, 2011).

Philip G. Cerny, Paradoxes of the Competition State: the Dynamics of Political Globalization, 32 GOVERNMENT AND OPPOSITION 2, 1997.

RICHARD RORTY, ACHIEVING OUR COUNTRY: LEFTIST THOUGHT IN TWENTIETH-CENTURY AMERICA (1998).

Sabrina Ragone, Constitutional Effects of the financial crisis at European and National level: a comparative overview, REVISTA GENERAL DE DERECHO PÚBlico COMPARADO, No. 15, 2014. 
T. Fougner, The State, international competitiveness and neoliberal globalization: is there a future the competition State?, 32 REVIEW OF INTERNATIONAL STUDIES 1, 2006.

William van Lear, Portfolio Shifts, Asset Price Declines, and Liquidity Lock Understanding the 2007-2009 Financial Crisis, 39 INTERNATIONAL JOURNAL of Political ECONOMY 3, 2010.

Peter Häberle en el Siglo XXI Peter Häberle no Século XXI Peter Häberle in the XXI Century Submetido em: 2016-05-29 